\title{
Insubordinación, deserción y traición a la patria.- El incidente Tucker con los marinos peruanos, 1866
}

\section{Insubordination, desertion and betrayal to the nation. - The Tucker incident with Peruvian navy officers, 1866}

\author{
Michel Laguerre Kleimann ${ }^{1}$ \\ Corbett Centre for Maritime Policy Studies (miembro asociado) \\ King's College London
}

\section{Resumen}

La victoria militar que el Perú obtuvo sobre la escuadra española frente al Callao (2-V-1866) significó el momento de mayor popularidad para la todavía nueva dictadura del coronel Mariano Ignacio Prado. Sin embargo, los sucesos que ocurrieron a raíz del nombramiento del marino norteamericano John R. Tucker como jefe de la División Naval Peruana de la Escuadra Aliada, evidenciaron que el gobierno de Prado no contaba con la solidez y legitimidad que una victoria militar de la magnitud mediática producida luego del 2 de mayo podría proporcionar al régimen dictatorial. De hecho, este gobierno duró menos de tres años.

1 Miembro de la Marina de Guerra del Perú. A su vez es miembro Colaborador del Centro de Estudios Estratégicos Marítimos del Instituto de Estudios Histórico-Marítimos del Perú.

Correo electrónico: mlaguerrek@gmail.com 
Palabras clave: Consejo de Guerra, marinos peruanos, John R. Tucker, Mariano I. Prado, Combate del 2 de Mayo de 1866.

\section{Abstract}

The Peruvian's triumph against the Spanish fleet in the battle of Callao (2-V-1866) created the most popular moment in the still-fresh dictatorship of Colonel Mariano Ignacio Prado. Nevertheless, not even this outstanding victory could help overcome the lack of strength and legitimacy of Prado's regime, as evidenced by the events that occurred in reaction to the appointment of American Rear Admiral John R. Tucker as chief of the Peruvian Naval Force of the Allied Task Force. Indeed, Prado's government lasted no more than three years.

Keywords: Court Martial, Peruvian Naval Officers, John R. Tucker, Mariano I. Prado, Naval Battle May 2 of 1866.

$$
* * *
$$

\section{Hipótesis:}

A pesar de la enorme popularidad a nivel sudamericano que la dictadura de Mariano Ignacio Prado obtuvo como consecuencia de la victoria del combate naval del 2 de mayo en el Callao, el apresamiento y enjuiciamiento de los marinos peruanos de la Escuadra Aliada a raíz del nombramiento de John R. Tucker tuvo una sentencia contraria a los deseos del dictador. Este hecho evidenciaría la debilidad e impopularidad creciente de su régimen. 


\section{Antecedentes $^{2}$}

Luego de la victoria del combate naval del 2 de mayo de 1866 en el Callao, el Perú festejó el triunfo -así como en el resto de países sudamericanos- con un júbilo libertario propio de la época de la independencia. Los protagonistas de estas jornadas fueron aclamados por el pueblo y reconocidos por sus méritos, mientras que artículos periodísticos incitaban al orgullo y ego nacional con frases como: "El Perú se ha ostentado ese día al nivel de los más grandes pueblos de la historia [...] pudo recordar en esa hora el nombre de las Termópilas y de Numancia" (El Comercio, lunes 2 de julio de 1866, 2da. edición, número 9016).

Debe recordarse que el 2 de mayo de 1866 la escuadra española comandada por el brigadier Casto Méndez Núñez fue derrotada por las fuerzas peruanas en la bahía del Callao. Ocho días después, el pabellón hispánico se alejó de la isla de San Lorenzo comunicando a la Legación británica que "quedaba levantado el bloqueo” (Romero Pintado 1984: 690)³.

2 Agradezco a Miguel Alberto Novoa Cipriani, estudiante de doctorado de historia de América Latina en la Universidad de California, Davis, por la lectura y sugerencias a la versión previa de este artículo.

3 Uno de los primeros historiadores navales y guardiamarina hasta el 23 de enero de 1867, Rosendo Melo, sostuvo que el día 10 de mayo, E.W. Roberts, cónsul británico anunciaba la suspensión del bloqueo (Melo 1911: 37). Por otra parte, el capitán de fragata Manuel I. Vegas García sostuvo que la comunicación del levantamiento del bloqueo se realizó el 9 y que solo fue hecha al cónsul de Brasil (Vegas García [1929] 1973: 130). Lo concreto es que la comunicación de Casto Méndez está fechada el 9 de mayo y dirigida al decano del cuerpo diplomático, señor John Barton, quien figura como encargado de negocios de su majestad la reina de la Gran Bretaña. En ella le indicaba que "[...] desde esta fecha queda levantado el bloqueo del Callao [...]” (Aranda 1896 VI: 868). 
La noticia fue recibida con gran júbilo y festividad tanto en el Callao como en Lima así como en Quito, La Paz, Santiago y demás ciudades sudamericanas ${ }^{4}$. De hecho, el 16 de mayo, el enviado extraordinario y ministro plenipotenciario del Perú en Chile, José Pardo y Aliaga, informó al canciller Toribio Pacheco que: "No hay recuerdo en el país de demostraciones más unánimes de júbilo que las que se han hecho por la victoria; ni honras fúnebres más suntuosas que los que se han hecho a nuestros mártires" (Basadre 1961 IV: 1601-1602).

Por otro lado, "también hubo grandes manifestaciones oficiales y populares en La Paz y en otras ciudades de Bolivia [... El día 17 fue declarado fiesta cívica [...] el 2 de mayo fue fiesta nacional boliviana [...] [En Quito] hubo repique general de campanas y los pabellones peruano, ecuatoriano, chileno y boliviano ondearon en numerosos establecimientos públicos y casas de la ciudad" (Basadre 1961 IV: 1601-1602).

\section{Preparativos}

Sobre las causas que originaron esta guerra internacional, con Bolivia, Chile, Ecuador y Perú por un lado, y el reino de España por el otro, Jorge Basadre las clasifica en dos grupos. Las ocultas y las visibles, entre las que se destacan "los intereses y presiones de la política interna que llevaron a adoptar actitudes vehementes en la política internacional" y "el poco tino, el deseo de crear o de agravar conflictos y hasta las extravagancias de algunos di-

4 "Colombia, Venezuela, Ecuador y Bolivia se solidarizaron moralmente con Perú y Chile, pero no pudieron o no alcanzaron a contribuir materialmente a la guerra (Barrios 1970: 226). 
plomáticos participantes en las negociaciones entre España, el Perú y Chile”, respectivamente (Basadre 1961 III: 1466).

Dentro de los preparativos defensivos que se establecieron al comienzo de la crisis diplomática de 1864, se envió a oficiales de marina a Europa con el objetivo de comprar los buques necesarios en caso estallase el conflicto con España.

El capitán de corbeta Aurelio García y García y el teniente primero Miguel Grau “viajaron a Londres en enero de 1864 (antes que fueran ocupadas las isla de Chincha, el 14 de abril de 1864) para adquirir elementos navales. Luego fue enviado con el mismo objeto el capitán de navío José María Salcedo a cuya opinión se dio autoridad decisiva $[\ldots]$ "..

En esta comisión surgieron serios y duraderos rencores que derivaron en acusaciones motivadas por los diferentes puntos de vista entre Salcedo, García y García, Marquina, y otros. Si bien el detalle de estos tensos intercambios públicos de palabras no es de interés en el presente trabajo, ayudarán a entender parte del desarrollo de los eventos relacionados con la prisión de los marinos peruanos debido a la alta sensibilidad de los involucrados en el caso de la contratación del contralmirante estadounidense John R. Tucker ${ }^{6}$.

5 "[De hecho] para adquirir ambos barcos [Unión y América] hubo necesidad de vencer los reparos de Salcedo en tanto que el juicio de García y García y de Grau, lo mismo que el de Federico Barreda, ministro en Francia e Inglaterra, fueron favorables a la operación" (Basadre 1961 IV: 1522).

6 "García y García acusó a Salcedo por su conducta desde la captura de las islas de Chincha por los españoles y por actitudes posteriores incluyendo las que llamó 'escapada a Europa en 1867' y 'fuga a Chile en 1869'. Lo llegó a calificar como ‘traidor y cobarde que huyendo 
El 28 de febrero de 1865, el prefecto del departamento de Arequipa, coronel Mariano Ignacio Prado (Cabello 1865: 187) se levantó contra el gobierno de Pezet y firmó el "Acta revolucionaria de Arequipa", en el que reprochó el tratado Vivanco-Pareja así como la actitud del presidente ante la situación producida por la toma de las islas de Chincha por el jefe de escuadra Luis Hernández Pinzón y Álvarez.

El movimiento contó con la simpatía de parte de la oficialidad naval, destacando entre ellos Lizardo Montero Flores. Este había sublevado en Arica al vapor Lerzundi', lo que ocasionó que el 24 de junio de 1865 fueran tomados para las fuerzas pradistas la fragata $A$ mazonas ${ }^{8}$, el vapor Tumbes $^{9}$ y la corbeta América. "A poco, la Unión, corbeta gemela de la América, fue ganada al mismo bando en Valparaíso, por el propio ministro peruano en Santiago, general Fermín del Castillo y por el cónsul en Valparaíso (Basadre 1961 IV: 1552) ${ }^{10}$.

del campo del honor y sustrayéndose al de la justicia, únicos en que los caballeros y hombres de bien deben arreglar sus diferencias' [...] En el viaje del Huáscar de Liverpool a Valparaíso, Salcedo separó de su cargo al segundo comandante del monitor, José M. Marquina” (Basadre 1961 IV: 1625).

7 Su comandante era el capitán de corbeta Lizardo Montero (Cabello 1865: 259).

8 Su comandante era el capitán de navío Francisco Sanz (Cabello 1865: 259).

9 Su comandante era el teniente primero Juan G. More (Cabello 1865: 259). Al siguiente año estuvo bajo el comando del capitán de corbeta Juan José Raygada (Cabello 1866: 221).

10 El capitán de navío Juan José Panizo y Talamantes "fue muerto en la sublevación que estalló en la Fragata de guerra Amazonas cuyo buque montaba como Comandante Gral; [...] entonces investia [sic] el empleo de Contra Almirante", [...] "Ni yo, ni mis oficiales quebrantaremos el Juramento que hemos prestado ante la Nación de 
Pezet se quedó con la fragata Apurímac, el transporte Chalaco, el blindado $L o a^{11}$ y el monitor Victoria ${ }^{12}$. Al triunfar la revolución de Prado, los marinos que permanecieron leales a Pezet fueron borrados del escalafón (Basadre 1961 IV: 1624).

Las fuerzas revolucionarias -desde el 25 de junio bajo el mando del general Pedro Diez-Canseco- se reunieron en Chincha. Entre los militares se encontró un grupo compacto de civiles liberales como José Gálvez, Toribio Pacheco, José María Quimper, José Casimiro Ulloa, entre otros (Basadre 1961 IV: 1561) ${ }^{13}$. Según las Memorias de Echenique, fue desde este lugar que Diez-Canseco declaró la guerra a España el 12 de octubre de 1865 (Echenique 1952 II: 273-275).

El domingo 26 de noviembre de 1865 se efectuaron votaciones en Lima que eligieron a Prado como jefe supremo pro-

defender sus instituciones legales y por consiguiente su dignidad [...] Seremos consecuentes á ese Juramento hasta nuestros últimos momentos [...]". Oficio de Panizo al Gobernador Comandante Militar de Arica, de fecha 4 de mayo de 1865. Expediente Juan José Panizo y Talamantes, caja p3, sobre p0088, fol. 23 y 51 Archivo Histórico de Marina (A.H. de M).

11 Su comandante era el capitán de fragata Manuel Ferreyros (Cabello 1865: 259). Al siguiente año estuvo bajo el comando del capitán de corbeta Camilo Carrillo (Cabello 1866: 221). Anteriormente sufrió una varadura bajo el comando del capitán de corbeta Juan M. Garrido. (El Comercio, domingo 8 de julio de 1866, número 9022).

12 Su comandante era el capitán de corbeta Ruperto Alzamora (Cabello 1865: 259). Al siguiente año estuvo bajo el comando del capitán de corbeta Antonio Valdivieso (Cabello 1866: 221).

13 Gálvez "era el alma de la Dictadura y sin él ella no podía subsistir, siendo el juicio de muchos que, si hubiera sobrevivido al 2 de Mayo, se habría hecho el Dictador (Echenique 1952 II: 282). El pensamiento de Pacheco -por otro lado- no fue liberal, "corresponde más bien a un conservadurismo progresista" (Basadre 1961 IV: 1879). 
visorio de la República. Fernando Casós, Toribio Casanova, Juan Francisco Pazos ${ }^{14}$ y Carlos María Elías de la Quintana ${ }^{15}$ aplaudieron el dictamen (Wagner 1981: 310) (Basadre 1961 IV: 1569) ${ }^{16}$. Prado asumió el mando con el título de dictador el 28 de noviembre.

\section{Formación de la Escuadra Aliada}

El 24 de setiembre de 1865, la Cámara de Diputados de Chile autorizó al Ejecutivo declarar la guerra a España (Wagner 1981: 279). Es así que un grupo de profesionales fueron enviados por la cancillería de Santiago a Estados Unidos de Norteamérica (Benjamín Vicuña Mackenna), Colombia y Venezuela (Manuel Antonio Matta), Perú (Domingo Santa María), entre otros para buscar apoyo (Barrios 1970: 226) ${ }^{17}$.

En el viaje a sus países de destino, Vicuña Mackenna se adelantó por días a Santa María, llegando al Perú donde conoció a José Gálvez Egúsquiza. El 10 de octubre se reunió en Pisco con Mariano Ignacio Prado y Lizardo Montero para estudiar la posibilidad de enviar a Chile parte de la escuadra peruana

14 Secretario de los Síndicos (Augusto de Althaus y Francisco Lazo) de la Municipalidad de Lima en 1866 durante la alcaldía de Antonio Salinas (Cabello 1866: 105). En 1867 fue regidor (Cabello 1867: 102).

15 "hijo de Domingo Elías y cuñado de Lizardo Montero. Más tarde se hará compadre de Miguel Grau" (Thorndike 2006: 585).

16 "Pezet y sus principales colaboradores se asilaron el 8 de noviembre [1865] en la corbeta de S.M.B. Shear Water" (Basadre 1961 IV: 1564).

17 Mario Barrios califica la labor diplomática de Álvaro Covarrubias Ortúzar (canciller chileno) como torpe y que las misiones nombradas por este fueron desatinadas (Barrios 1970: 227). 
rebelde a Pezet: Amazonas, Unión, América y Tumbes (Wagner 1981: 280-281).

Por su parte, el agente especial con rango de ministro, Domingo Santa María, "caló más hondo en la sociedad limeña que todos sus antecesores juntos [...] Comprendiendo que la indecisión política era fatal para el Perú, cargó los dados en favor de Prado, del cual era personalmente amigo" (Barrios 1970: 228).

De hecho, Santa María encontró acogida a los planes que tenían Prado, Montero, Diez Canseco y el canciller del movimiento revolucionario, José Manuel La Puente (todos acampados en Chincha Alta, al sur de Lima) respecto al envío de los buques de la Armada Peruana a Chile en clara señal de solidaridad regional contra las fuerzas españolas. La dictadura de Prado dio a la misión de Santa María "una segura garantía de buen éxito" (Wagner 1984: 304).

Sin embargo, la situación interna aún estaba por definirse debido a que Pezet continuaba como presidente de la República y con el ejército y parte de la marina a su favor. A esto se sumaron las serias fricciones entre Montero (nombrado como jefe de la escuadra peruana) y Manuel Villar Olivera en relación con la planificación de las operaciones en el sur, siendo este abofeteado por el primero el 19 de octubre en una reunión de comandantes de los buques a órdenes de Prado (Wagner 1984: 2187; Basadre 1961 IV: 1562) ${ }^{18}$.

18 "Montero, jefe de la escuadra, era acaso el más joven de sus capitanes. No había llegado a esta posición por merecimientos a causa de su competencia técnica, o por acción de guerra, sino gracias a la revolución y 
Por otro lado, y según el análisis de Santa María, el único oficial de la Armada Peruana que podría disputar el mando de la flota aliada sería el chileno José María Salcedo, quien en enero de 1866 continuaba en Gran Bretaña supervisando la construcción del Huáscar. Es así que en una reunión con Prado y su gabinete propuso el orden en el mando de la Escuadra Aliada: "Almirante Blanco Encalada, Almirante Simpson, Capitán de Navío Salcedo y Capitán de Navío Williams" (Wagner 1981: 315-316). Ninguno era peruano.

El 3 de diciembre zarparon del Callao con rumbo a Valparaíso las fragatas Apurimac y Amazonas al mando de los capitanes de navío Manuel Villar y Hercilio Cabieses. Las corbetas América y Unión iban comandadas por los capitanes de corbeta Manuel Ferreyros Senra y Miguel Grau Seminario (Cabello 1866: 221; Wagner 1981: 316). El 16 de enero de 1866, José Gálvez, ministro de Guerra y Marina, le dio instrucciones a Villar en su condición de jefe de la escuadra ${ }^{19}$. Tres días después, estas fueron actualizadas haciendo hincapié en el cumplimiento del artículo III del Tratado OfensivoDefensivo firmado con Chile.

Es necesario leer el Artículo III del Tratado de Alianza Ofensiva Defensiva con relación al mando y jerarquía entre los marinos (peruano, chilenos y extranjeros) considerando las aguas donde navegaría la Escuadra Aliada ${ }^{20}$. Nótese que

buena estrella $[. .$.$] Su nombramiento no era, pues, popular entre sus$ subordinados" (Wagner 1981: 287-288).

19 Gálvez a Villar, 16-I-1866. Archivo del Ministerio de Relaciones Exteriores del Perú. https://apps.rree.gob.pe/portal/catalogoradi.nsf/Ficha_ Catalogo.xsp?action $=$ openDocument\&documentId $=3226$

20 El Tratado de Alianza Ofensiva y Defensiva entre Perú y Chile fue firmado el 5 de diciembre de 1865. "La unión de fuerzas navales peruanas 
el término extranjero se emplea para indicar a la persona no oriunda de los países firmantes:

Las fuerzas navales de ambas Repúblicas, sea que obren en combinación o separadamente, obedecerán, mientras se mantenga la presente guerra, provocada por el Gobierno español, al Gobierno de aquella en cuyas aguas dichas fuerzas navales se hallaren.

El jefe de mayor graduación, y, en caso de haber muchos de una misma graduación, el más antiguo entre ellos que se encontrara mandando cualquiera de las escuadras combinadas, tomará el mando de ellas, siempre que dichas escuadras obraren en combinación. Sin embargo, los Gobiernos de ambas Repúblicas podrán conferir, de mutuo acuerdo, al Jefe nacional o extranjero que consideren más competente (Wagner 1981: 314).

Sobre el éxito del envío de las fuerzas navales peruanas a Chile, Basadre no está a favor de la supuesta gran influencia que Santa María tuvo en los hombres de la dictadura. Por el contrario, los presenta imbuidos por las circunstancias externas e internas que hicieron confluir los intereses de estos liberales con los de Chile. Por ello, cuando Prado declaró la guerra contra España, el 13 de enero de 1866, sostuvo en ese Decreto:

Que independientemente de los motivos especiales que tiene el Perú para exigir al gobierno de España la reparación de las graves ofensas que le ha irrogado, ha debido reputar y reputa como suya la cuestión que ese gobierno ha promovido a Chile, y en consecuencia, se ha firmado, aprobado y ratificado un tratado de Alianza ofensiva y defensiva entre

y chilenas va desde diciembre de 1865 hasta enero de 1868" (Romero Pintado 1984: 699). 
ambas Repúblicas [...] Art. I. Se declara a la República en estado de guerra con el Gobierno de España (Aranda 1896 VI: 712).

\section{Causas del arresto}

Los periódicos publicaban arengas contra España e incentivaban la ofensiva hacia sus dominios: "Si la guerra en el Pacífico ha terminado, que el grito unánime de la América grande y unida sea en consecuencia ¡Guerra en el Atlántico!” (El Comercio, 2 de julio de 1866, 2da. edición, número 9016). El mismo Prado se dirigió a la nación dando cuenta de la retirada de la escuadra hispánica, así como de la victoria completa sobre la misma, e invocaba a no bajar la guardia pues "la guerra no ha concluido" (Aranda 1896 VI: 869).

Prado buscó llevar a la Escuadra Aliada a dominios hispánicos como las Filipinas. Para esto, decidió contratar "a un experto en táctica naval”: John R. Tucker (Melo 1911: 48). La elección del virginiano resulta, a primera vista, confusa debido a los recientes acontecimientos en los que los oficiales navales peruanos demostraron lealtad a la opción que representaba Prado ante la situación internacional ocasionada por la escuadra española ${ }^{21}$. "Son inconcebibles los motivos que hallan inducido al Jefe Supremo a tomar tan extraña medi-

24 da, y nos parece que no hay razones plausible" (El Comercio, 20 de setiembre de 1866, número 9098). Incluso, podría ser

21 Para Jorge Ortiz Sotelo, Prado lo contrató con la finalidad de tener un mando unificado que no "despertase recelos entre los peruanos y los chilenos", como de alguna manera habría ocurrido antes y después de Abtao y contar con marinos más experimentados de los que se acababan de batirse en Abtao y el Callao (Ortiz Sotelo 2003: 132). 
considerado como un "error de múltiples consecuencias" (de la Puente 2003: 114).

Los contrarios con el proceder de los marinos contrastaron lo sucedido con la escuadra en tiempos de la lucha por la independencia. Por ejemplo, el jefe de ambas escuadras, Manuel Blanco Encalada -natural de Buenos Aires-, era una personalidad con prestigio profesional y político tanto en Chile, Bolivia como en el Perú, quien en la cúspide de su fama como marino en la época de la independencia "sin la menor vacilación le entregó el mando de la escuadra chilena [a Cochrane] (Romero Pintado 1984: 715).

Los acusadores de Montero y compañía les reprocharon el hecho de que: "Cuando está vivo aun entre nosotros el recuerdo de los incalculables resultados obtenidos en la guerra de la independencia, con la feliz adquisición de Cokrane [sic] [...] venís aquí haciendo alarde de vuestra desobediencia al Gobierno" (El Comercio, 6 de octubre de 1866, número 9113).

Sin embargo, la elección de Tucker, de quien se dijo que ningún oficial aliado podía rivalizar con él en lo concerniente a conocimientos sobre blindados y armas modernas" (Werlich 2010: 126) no se debería a una decisión que buscara desconocer las habilidades de los marinos peruanos, sino, al contrario, complementarla con la experiencia en el comando de buques blindados que la guerra de secesión estadounidense brindó a marinos como Tucker. Más aun, en momentos en que el Perú había adquirido al Huáscar y a la Independencia, "cuando el sistema de blindaje es un elemento de guerra marítimo que en la actualidad solo los Americanos del Norte conocen á [sic] fondo [...]" (El Comercio, 6 de octubre de 1866, número 9113). 
Lo cierto es que la dictadura sostuvo, en relación a la contratación de Tucker, que: "por muy acreditado que fuese el valor de nuestros marinos, no era suficiente para revestirlos de las cualidades que son indispensables para dirigir una poderosa escuadra [...] resultando de allí el imperioso deber en que se hallaba el gobierno de sacrificar cualquier susceptibilidad de nacionalismo [...] para lo cual era necesario confiar la escuadra a un jefe de acreditada experiencia" (Secretaría del Ministro de Marina 1984: 94-95).

En la carta privada que el dictador le envió al comandante de la Independencia, el 26 de junio de 1866, decía que Tucker "es nada menos que la segunda notoriedad entre los marinos de la Gran República del Norte" (García y García 1867: documento número 3).

Este nombramiento fue a todas luces controversial considerando las previas actitudes a favor de Prado por parte de miembros de la Armada, como las que tuvo el comandante de la Unión Miguel Grau, quien se resistió ante la solicitud de su padre de no adherirse a la revolución de Arequipa, evidencian que los oficiales de marina apostaron su conciencia y libertad por lo que realmente creían, a pesar de que la disyuntiva inicial de romper con el statu quo fue dramática y angustiante.

Por otro lado, los combates navales en Abtao y en el Callao evidenciaron claramente el profesionalismo, lealtad y valor de los marinos peruanos contra las fuerzas extranjeras de un imperio europeo. Asimismo, la Armada contaba con oficiales del prestigio de Antonio de la $\mathrm{Haza}^{22}$, Domingo Va-

22 En 1865 era el Mayor de Órdenes y Comandante de Arsenales (Cabello 1865: 258). "No dirá por cierto que nos faltan jefes experimentados y 
lle Riestra ${ }^{23}$, Alejandro Muñoz, entre otros (García y García 1867: 5; Melo 1911: 48; Vegas García 1973: 141).

Sin embargo, las tensiones del mes de marzo de 1866 ocasionaron roces entre el comandante general de la escuadra (Juan Williams Rebolledo) y el jefe de las fuerzas navales peruanas (Manuel Villar Olivera) ${ }^{24}$. Esto se alivió al ser ambos relevados el 6 de junio por el vicealmirante Manuel Blanco Encalada y por el capitán de navío José María Salcedo, respectivamente (Romero Pintado 1984: 715). Cinco días después, la Escuadra Aliada zarpó rumbo a Valparaíso y arribó a dicho puerto el 16 de junio a las 20:30 horas (Vegas García 1973: 139; El Comercio, 8 de julio de 1866, número 9022).

El 23 de junio, Montero arribó a Valparaíso para asumir el mando del monitor Huáscar, así como el de la División Naval Peruana en reemplazo de Salcedo, quien a los dos días zarpó rumbo al Callao para asumir la Comandancia General de Marina (Vegas García 1973: 140)25. Romero Pintado asume

capaces, porque afortunadamente tenemos varios como nos demuestra la experiencia" (El Comercio, 20 de setiembre de 1866, número 9098).

23 Ascendió a contralmirante el 14 de abril de 1854, a los 45 años de edad. Expediente Domingo Valle Riestra, caja v2, sobre v0075, fol. 50 (A. H. de $\mathrm{M}$ ).

24 "El estado de incomprensión que desde los contactos iniciales de 1865 había existido entre los jefes de los divisiones peruana y chilena que constituía la Escuadra Aliada, había conducido a la crisis" (Romero Pintado 1984: 709). Sobre el incidente del cañoneo a la Unión por parte del aliado Chile, véase Vegas 1973: 135.

25 Error de Rosendo Melo al afirmar que esta designación se debió a un descuido o desatino, pues según él, Montero habría sublevado en Arica a la Apurimac contra Pezet, cuando el comandante de esta, Salcedo, se encontraba en tierra (Melo 1911: 49). Lo cierto es que el 27 de mayo de 1864, Salcedo fue nombrado en comisión a Estados Unidos como a Eu- 
que Montero sabía antes de zarpar desde el Callao que el gobierno deseaba contratar a Tucker. De hecho, el virginiano llegó a Lima el 17 de junio y zarpó en julio rumbo a Chile (Romero Pintado 1984: 717-718).

El 26 de junio, Prado envió cartas personales a los comandantes Montero, Ferreyros, Grau y Aurelio García y García. A este último --comandante de la Independencia-, luego de comunicarle la contratación de Tucker, le sostuvo que: "Espero que usted, conocedor de las sanas y patrióticas aspiraciones del Gobierno y en obsequio de su patria, lo respete y contribuya a que se le respete y considere en su calidad de tal Contra-Almirante de la Escuadra [...]" (Romero Pintado 1984: 718).

Como se ha mencionado, Prado nombró a Tucker comandante de la escuadra peruana que formaba parte de la Escuadra Aliada constituida a raíz del Tratado de Alianza Ofensiva y Defensiva entre Perú y Chile. Montero "protestó contra esta designación calificándola como una ofensa a marinos antiguos, capaces y patriotas" y ocasionó que el gobierno de Chile se escandalizase (Werlich 2010: 130-132).

José Pardo y Aliaga informó a Toribio Pacheco que Tucker arribó a Valparaíso en el vapor Paita el 23 de julio, así como de las reuniones y acciones que tuvo que hacer para tratar de subsanar la situación. El diario El Comercio comentó que ante la negativa de los oficiales peruanos de reconocerlo se conformó una junta integrada por "Montero, el contra-almirante Tucker y el ministro del Perú (José Pardo y Aliaga)

ropa por un periodo de dos años. Capitán de Navío José María Salcedo. Relaciones Historiadas. Libro Copiador nro. 1 fol. 28. (A.H. de M). 
que habrían resuelto que para dar fin a la cuestión se enviara la escuadra al Callao" (El Comercio, 3 de agosto de 1866, número 9048).

En el ínterin, el gobierno nombró en comisión a Valparaíso al secretario de Hacienda y Comercio Manuel Pardo y Lavalle (Basadre 1961 IV: 1626). Salcedo volvió a ser designado como jefe de la división peruana en reemplazo del ahora arrestado Montero (Vegas García 1973: 141).

Pardo arribó a Valparaíso el 3 de agosto con la Resolución Suprema de fecha 23 de julio de 1866 firmada por Pedro Bustamante, Secretario de Guerra y Marina, así como por el mismo Prado, en la cual se ordenaba a los marinos de la división peruana que se sometieran "a las inmediatas órdenes del Secretario de Hacienda y Comercio, quien procederá en seguida a cumplir las indicaciones del Supremo Gobierno" (Arosemena 1975: 47).

Manuel Pardo les dirigió una nueva comunicación en la que les indicaba que el capitán de navío José María Salcedo había sido nombrado comandante del Huáscar; el capitán de navío José María García, comandante de la Independencia; el capitán de fragata Juan Pardo de Zela, comandante de la América; mientras que el capitán de corbeta Camilo Carrillo, comandante de la Unión (Arosemena 1975: 47). Pardo ordenó a Montero que hiciera reconocer como comandantes a dichos jefes (López 1947: 94) y lo hizo de manera oficial según la ordenanza (García y García 1867: documentos número 11, 12,13 y 14).

El 28 de agosto, el gobierno de Prado aprobó el nombramiento realizado por Manuel Pardo en favor de Salcedo 
como comandante general de la División Naval del Perú de la Escuadra de Operaciones del Sur ${ }^{26}$. A los pocos días, mandó comunicar a Tucker (segundo comandante de la Escuadra Aliada) que Salcedo era requerido con carácter de urgencia para realizar una comisión de importancia en Europa, "quedando usted autorizado para nombrar un Jefe que provisionalmente se encargue del mando del monitor Huáscar"27. Salcedo arribó al Callao el 25 de setiembre ${ }^{28}$.

Mientras esto sucedía, el 5 de agosto, Manuel Pardo comunicó a los jefes, oficiales y guardiamarinas que continuaban firmes en su posición de no trabajar bajo las órdenes del contralmirante John Tucker que se presentasen dentro de las 24 horas "a bordo de los buques a donde harán la renuncia, por el conducto regular [...] Los que no cumpliesen con venir quedarán declarados desertores de la Armada al frente del enemigo".

Al respecto, y ante lo negativo o revoltoso que pudieran verse estos acontecimientos de relevos en plena guerra, el pro-

26 Libro Copiador de notas a la Comandancia General de Marina y Mayoría de Órdenes. Elcorrobarrutia, Director de Marina, al Mayor de Órdenes encargado de la Comandancia General del Departamento Marítimo del Callao. 28-VIII-1866, fol. 12. (A.H. de M.).

27 Dirección de Marina. Copiador de notas a diferentes autoridades, Elcorrobarrutia al Contra Almirante 2do Jefe de la Escuadra Aliada, 4-IX1866, fol. 17 (A.H. de M.) Salcedo estuvo en Londres, tal cual se aprecia en las órdenes que el Secretario de Guerra y Marina dio en febrero de 1867 a Nicolás del Portal para la adquisición de "tres pequeños vapores de ruedas". Dirección de Marina. Copiador de notas a diferentes autoridades, Pedro Bustamante [Secretario de Guerra y Marina] al Capitán de Corbeta Nicolás [del] Portal, 13-II-1867, fol. 144 (A.H. de M.).

28 Notas de la Secretaría de Guerra y Marina del año 1866. Nro. 1084, $25-$ IX-1866, fol. 53 (A. H. de M.). 
pio Miguel Grau se encargó de aclararlos en una carta a Benjamín Vicuña Mackenna de fecha 6 de diciembre de 1878:

La Marina peruana no estaba sublevada [...] porque los que estábamos a cargo de esos buques, en ningún caso hubiéramos ofrecido un espectáculo que con justicia califica Ud. como fatal indisciplina [...] los marinos peruanos creímos de deber inexcusable hacer nuestras observaciones y manifestar nuestra resolución de rescindir el mando de los buques si se insistía en someternos a una tutela que no vacilamos en calificar de humillante. Insistiendo el gobierno en su propósito nombró a otros compañeros de armas que debían reemplazarnos y comisionó al esclarecido señor Pardo para entregar el mando de los buques a los elegidos [...] [a su arribo] todos los comandantes fuimos a recibirlo y saludarlo; nos pusimos en el acto a sus órdenes y en la más cortés y familiar entrevista, resignamos ante él el mando de nuestros respectivos buques y regresamos a entregarlos y hacer reconocer por las tripulaciones a los llamados a sucedernos (de la Puente 2003: 115-116).

José Rufino Echenique, cuyo hijo Juan Martín se encontraba entre los oficiales que desconocieron a Tucker, relató en sus memorias que ante el arribo de Pardo a Valparaíso los marinos peruanos fueron a visitarlo a bordo como "testimonio de respeto" y que "estaban prontos a obedecer lo que el Gobierno disponía pero también resueltos, por honra y propio decoro, a separarse del mando de los buques en que se hallaban, cuya dimisión le hacían" (Echenique 1952 II: 282-283).

Luciano Benjamín Cisneros relató la misma situación cuando pronunció ante el Consejo de Guerra que Pardo encontró "la más completa calma, la más laudable docilidad en los marinos, quienes sin réplica aceptaron a los nuevos Comandantes destinados a reemplazarlos" (Secretaría del Ministro de Marina 1984: 86). 
Por su parte, Pardo volvió el 17 de agosto al Callao, a bordo de la Independencia (Melo 1911: 50). Diez días después le escribió a José Antonio de Lavalle que "a juzgar por las apariencias es ahora remoto todo trastorno político, sobre todo después que los Marinos se sublevaron con el Almirantazgo del yankee, han tenido que capitular, entregar sus buques y someterse a un consejo de guerra" (Archivo José Pardo y Barreda, cortesía de José Carlos Martín en de la Puente 2003: 119). Los oficiales renunciantes fueron embarcados en el vapor transporte Callao (Arosemena 1941: 47; López 1947: 95).

\section{Arribo al Callao e inicio del arresto}

El Callao zarpó el 8 de agosto desde Valparaíso y arribó a las aguas chalacas el 15 de agosto a las 17:30 horas. Su comandante interino era Juan Guillermo More y traía consigo a "Montero y todos los jefes y oficiales que se negaron a reconocer al contra-almirante Tucker"' (El Comercio, 16 de agosto de 1866, número 9058).

La llegada de los acusados de insubordinación al Callao no fue comunicada por la Mayoría de Órdenes encargada de la Comandancia General de Marina al Secretario del Ramo, el cual mostró su desagrado llamándole fuertemente la atención por esa omisión. A los cuatro días, solicitó la relación de los jefes y oficiales que se negaron a servir bajo las órdenes del contralmirante Tucker ${ }^{29}$.

29 Jefes Militares.- "Cuando en una disposición se habla de jefes y oficiales, se entiende por jefes a los generales, coroneles, tenientes coroneles y sargentos mayores [...] Bajo la denominación de oficiales se comprende a todos los militares de los grados inferiores, desde capitán hasta subteniente" (García Calderón II 1879: 1177). 
Entre los oficiales se encontraron:

capitán de navío Lizardo Montero, capitán de fragata Manuel J. Ferreyros, capitán de fragata Miguel Grau, capitán de fragata Aurelio García y García, capitán de corbeta Julio Tellería, capitán de corbeta Ezequiel Otoya, capitán de corbeta Juan Cobián, capitán de corbeta Gregorio Pérez, capitán de corbeta Mariano J. Reyes, capitán de corbeta graduado Arístides Gonzales Vigil, teniente primero Felipe Mesa, teniente primero Francisco Charún, teniente primero Carlos Ferreyros, teniente primero Carlos Thorne, teniente primero graduado Enrique N. Alayza, teniente primero graduado Elías Aguirre, teniente segundo Narciso García y García, teniente segundo Ricardo Vera, alférez de fragata Gaspar Ureta, alférez de fragata Felipe La Torre Bueno, alférez de fragata Octavio Freyre, alférez de fragata Carlos Herrera, alférez de fragata Alejandro Sauri, alférez de fragata Eugenio Raygada, alférez de fragata Guillermo García y García, alférez de fragata Enrique Palacios, alférez de fragata Justiniano Cavero, alférez de fragata Arnaldo Larrea, alférez de fragata Samuel Sarrio, alférez de fragata Vicente Espinosa, alférez de fragata Luciano Arana, alférez de fragata Pedro Rodríguez, guardiamarinas Manuel Velásquez y José Cañote, contador Antonio B. Carrasco ,entre otros (Arosemena 1975: 51).

Esta fue aumentada más adelante con la inserción del alférez de fragata Nicanor Asín de la Unión, quien manifestó "no estar gustoso de prestar sus servicios bajo las órdenes del ContraAlmirante Tucker, 2do jefe de la Escuadra Aliada" "30. Por otro lado, el alférez de fragata Nicacio Aramburú desertó de la misma y fue dado de baja por recomendación del secretario en

30 Elcorrobarrutia, Director de Marina, al Mayor de Órdenes encargado de la Comandancia General del Departamento Marítimo del Callao, 16-VIII1866, fol. 7 / 20-VIII-1866, fol. 8 (A.H. de M.). Dirección de Marina. Copiador de notas a diferentes autoridades, Elcorrobarrutia al Juez Fiscal, Torrico, 2-X-1866, fol. 36 (A.H. de M.) Notas de la Secretaría de Guerra y Marina del año 1866. Nro. 1108, 29-IX-1866, fol. 53 (A. H. de M.). 
comisión, Manuel Pardo ${ }^{31}$. Este último oficial había luchado bajo el comando de Grau en el combate de Abtao (El Peruano, 6 de junio de 1866, tomo 50, número 52, p. 208).

Los cargos acusatorios fueron enviados por Pedro Bustamante, secretario de Guerra y Marina, al fiscal Joaquín Torrico el 17 de agosto. Estos fueron insubordinación, deserción y traición a la patria. Según la segunda edición del Diccionario de la legislación peruana de Francisco García Calderón, estos cargos significaron:

Deserción.- "individuos de tropa o de mar que deserten alejándose a media legua de su buque o cuartel [...] La deserción va acompañada de circunstancia agravante, cuando se comete en campaña o estando en guarnición, cuartel u otro destino en tiempo de guerra o pasando a país extranjero [...]” (García-Calderón 1879: 737).

Insubordinación.- "La falta de sujeción a la orden, al mando, imperio o dominio de otro. La falta de obediencia, respeto, sumisión y disciplina [...] la insubordinación importa solo una desobediencia; [...] para que haya insubordinación se requiere que haya superioridad legítima y que la orden del superior sea en asuntos del servicio” (García Calderón 1879: 1151).

Traición.- "El delito de traición se encuentra en el número de los que se cometen contra la seguridad exterior del Esta-

34 do [...] [por ejemplo] los peruanos que en estado de guerra, seduzcan oficiales, soldados o marineros, para que pasen al enemigo de la patria, o deserten de sus banderas, o cometan cualquier otro acto de traición [...] Hay además una traición

31 Dirección de Marina. Copiador de notas a diferentes autoridades, Elcorrobarrutia al Contra Almirante 2do Jefe de la Escuadra Aliada, 20-X1866, fol. 59 (A.H. de M.). 
indirecta que consiste en negarse a servir a la nación en tiempo de guerra" (García Calderón 1879: 1783).

Siguiendo a Echenique, quien era uno de los integrantes del Consejo de Guerra que vio la causa de los marinos enjuiciados, el dictador se encontraba "molesto" con la actitud y postura de estos y empeñado "en que se impusiera pena a esos jefes fundándose en que ello era necesario para la disciplina y respetabilidad del Gobierno” (Echenique 1952 II: 283).

De las 51 declaraciones recogidas por el fiscal Joaquín Torrico, fueron excluidos del juicio, el 26 de agosto, el capitán de corbeta graduado Guillermo Pareja, los capitanes de corbeta Juan y Toribio Raygada, el sargento mayor de artillería Vidal García y García, capitanes José Torre-Blanca y Juan M. Echenique, teniente W. Cabada, tenientes segundo Teodoro Otoya y Francisco Terry, alféreces de fragata José Benito Pitot y Francisco Larosa, el subteniente Manuel Andrade, contador Pedro Angulo, cirujanos de segunda clase Tito S. Melgar, Adán Melgar y el amanuense Adolfo King. El 5 de octubre, el alférez de fragata Alejandro Sauri fue absuelto (García y García, 1867: documentos número 10 y 15).

$\mathrm{Al}$ parecer el arresto a bordo del Callao no era estrictamente riguroso, tomando en cuenta que a los pocos días de su arribo varios de los oficiales enjuiciados fueron vistos en Lima a vista y paciencia de la pequeña y harto curiosa capital peruana. El Cercado contaba en ese año con 105,267 habitantes (Cabello 1866: 71). Uno de ellos fue el contador del Huáscar, Manuel B. Carrasco ${ }^{32}$.

32 Notas de la Secretaría de Guerra y Marina del año 1866. Nro. 967, 4-IX1866, fol. 11 (A.H. de M.) y Notas de la Secretaría de Guerra y Marina del año 1866. Nro. 1019, 11-IX-1866, fol. 25 (A. H. de M.). 
Sin embargo, el dictador no iba a dejar que se relajara la disciplina y menos sus órdenes de prisión. Se dispuso que estos fueran transbordados al vapor $S a c h a c a^{33}$ y a la presa española Pepita Victoriana, la cual debería fondear en la isla San Lorenzo $^{34}$. Sin embargo, por recomendación de la Mayoría de Órdenes encargada de la Comandancia General de Marina, estos serían depositados en la fragata Apurimac $^{35}$.

Aparentemente, el transbordo nunca se realizó pues al mes siguiente el director de marina comunicaba al mayor de órdenes que:

A llegado a conocimiento del Señor Secretario del Ramo, que algunos Jefes y oficiales de los que se hallan enjuiciados y arrestados a bordo del Vapor Callao en la isla de San Lorenzo, violan el arresto y se vienen diariamente a la capital, donde se les ve con el mayor escándalo, en los lugares más públicos, y en este concepto me ordena decir a Ud. averigue e informe después a ésta Dirección sobre la manera cómo avienen a lugar los hechos que quedan puntualizados.

El 31 de octubre se informó al coronel Joaquín Torrico, quien era el juez fiscal en comisión de la causa a los jefes y oficiales arrestados por no querer servir bajo las ordenes de Tucker, que se dispuso a la policía la captura de los prófugos del vapor y que los recluyan en el mismo ${ }^{36}$.

33 Su comandante era el capitán de corbeta Toribio Raygada (Cabello 1866: 221).

34 Elcorrobarrutia, Director de Marina, al Mayor de Órdenes encargado de la Comandancia General del Departamento Marítimo del Callao, 23VIII-1866, fol. 10 (A.H. de M.).

35 Elcorrobarrutia, Director de Marina, al Mayor de Órdenes encargado de la Comandancia General del Departamento Marítimo del Callao. 24VIII-1866, fol. 10 (A.H. de M.).

36 Dirección de Marina. Copiador de notas a diferentes autoridades, Elcorrobarrutia al Juez Fiscal, Torrico. 31-X-1866, fol. 69 (A.H. de M.). 
Estos "escapistas" fueron: capitán de corbeta graduado Arístides G. Vigil, tenientes primero Felipe Mesa, Federico Charún, Enrique N. Alayza, teniente primero graduado Elías Aguirre, tenientes segundo Narciso García y García y Ricardo Vera, alféreces de fragata Felipe La Torre Bueno, Gaspar Ureta, Carlos Herrera, Alejandro Sauri, Octavio Freyre, Guillermo García y García, Enrique Palacios, Justiniano Cavero, Arnaldo Larrea, Vicente Espinoza, Luciano Arana, Pedro Rodríguez y Samuel Sarria ${ }^{37}$.

El comandante del Callao, hasta el 13 de octubre, fue el capitán de corbeta Juan Guillermo More Ruiz, quien fue designado como comandante de la Unión, la cual se hallaba en Valparaíso conformando la división naval peruana de la Escuadra Alia$\mathrm{da}^{38}$. El de igual grado José Becerra fue designado como su relevo, el cual se hizo de manera acelerada por lo cual debió levantar su inventario y listado general del buque ${ }^{39}$.

37 Elcorrobarrutia, Director de Marina al Mayor de Órdenes del Departamento Marítimo del Callao, 31-X-1866, fol. 47. (A.H. de M.).

38 El 12 de octubre, Elcorrobarrutia informaba la relación de los jefes y oficiales que deben dotar los buques de la División Naval del Perú en la Escuadra Aliada: Comandante general de la división y de la fragata Independencia, capitán de navío José María García; segundo comandante de la Independencia, el capitán de corbeta Camilo Carrillo; comandante del monitor Huáscar, el capitán de navío graduado Alejandro Muñoz; segundo comandante el capitán de corbeta Marcelo Proaño; comandante de la corbeta América, el capitán de fragata Juan Pardo de Zela; segundo comandante, el capitán de corbeta Nicolás del Portal; comandante de la corbeta Unión, el capitán de corbeta Juan G. Moore [More]; segundo comandante de la Unión, el capitán de corbeta Ulises Delboy. El mayor de órdenes de la División Naval del Perú en la Escuadra Aliada fue el capitán de navío graduado Juan M. Fanning. Elcorrobarrutia, Director de Marina, al Mayor de Órdenes encargado de la Comandancia General del Departamento Marítimo del Callao. 12-X-1866, fol. 33 (A.H. de M.).

39 Elcorrobarrutia, Director de Marina, al Mayor de Órdenes encargado de la Comandancia General del Departamento Marítimo del Callao. 13- 
Becerra ignoraba las órdenes que el fiscal coronel Joaquín Torrico había impartido sobre los oficiales enjuiciados ${ }^{40}$. Al respecto, la Dirección de Marina informó a la Mayoría de Órdenes que en relación al trato, comunicación y disposiciones sobre los marinos arrestados, estos se encontraban a disposición de Torrico, siendo así que el comandante del Callao debía dirigirse a él en los asuntos relativos al juicio y las condiciones de arresto ${ }^{41}$.

Por otro lado, no es exacto presumir que los jefes y oficiales arrestados permanecieron incomunicados. Más aun debido a las diversas solicitudes que el propio gobierno les hacía en relación a diversa documentación oficial.

De hecho, parece que los marinos enjuiciados dejaron sus antiguos puestos a bordo de los buques de la Escuadra Aliada llevándose consigo algunos documentos y planos relacionados con los mismos. Algunas comunicaciones entre la Mayoría de Órdenes y la Dirección de Marina evidenciaron esta realidad, así como cierto desorden en el archivo documentario.

X-1866, fols. 35 y 39 (A.H. de M.). Tizón informó a Elcorrobarrutia que Becerra no asumió el mando del buque el 14 del mes "no habiendo podido llenar los requisitos de ordenanza en cuanto a la entrega con los documentos respectivos". Esto se debió a la partida inmediata de More rumbo a su nuevo destino como comandante de la Unión. Notas de la Secretaría de Guerra y Marina del año 1866. Nro. 1256, 17X-1866, fol. 91 (A.H. de M.).

40 Notas de la Secretaría de Guerra y Marina del año 1866. Nro. 1261, 18X-1866, fol. 92 (A.H. de M.).

41 Elcorrobarrutia, Director de Marina, al Mayor de Órdenes encargado de la Comandancia General del Departamento Marítimo del Callao, 19-X1866, fol. 41 (A.H. de M.). 
Por ejemplo, a finales de agosto se programó el ingreso de la fragata Independencia al dique en el Callao. El director del dique solicitó los planos de dicho buque "con el objeto de preparar los cabos y demás aparatos para recibirla”. El capitán de navío José Elcorrobarrutia, -director de marina desde el 28 de julio,-solicitó a la Comandancia General que recabe dichos documentos que estaban en posesión del ex comandante del buque, capitán de fragata Aurelio García y García $^{42}$. La respuesta se dio a los dos días cuando el comandante general llamó duramente la atención al director de marina:

Tengo la honra de pasar el despacho de Ud. adjunta a esta, Comunicaciones la que con fecha de ayer dirigí al capitán de fragata D. Aurelio García y García, pidiéndole los planos de la fragata blindada Independencia en la cual hallará Ud. el informe que ha emitido asegurando que en la Secretaría del ramo deben existir esos documentos pero que no obstante ha pedido [...] los trabajos de ese buque. Con este motivo llamo la atención a Ud. sobre el atrazo [sic] que sufren en la estafeta de la Capital las Comunicaciones, aun aquellas que como la de que me ocupo tiene el carácter de urgentísimo afín de que sirva recabar las ordenes correspondientes, para que no se repitan estas faltas que pueden atraer graves consecuencias al servicio. Alejandro Muñoz"43.

Anteriormente, el 17 de agosto, Salcedo solicitó los papeles de mar de la presa española Pepita Victoriana -capturada por la Independencia-. Como no se encontraron en las oficinas de la Secretaría de Guerra y Marina, el director de marina le or-

42 Elcorrobarrutia, Director de Marina, al Mayor de Órdenes encargado de la Comandancia General del Departamento Marítimo del Callao, 1-IX1866, fol. 13. (A.H. de M.).

43 Notas de la Secretaría de Guerra y Marina del año 1866. Nro. 950, 3-IX1866, fols. 6 y 7 (A.H. de M.). 
denó al comandante general de marina que le pregunte sobre estos documentos a Aurelio García y García ${ }^{44}$.

El 22 de agosto, Elcorrobarrutia le envió una comunicación a Salcedo donde le transcribía la respuesta del mayor de órdenes encargado de la Comandancia General del Departamento Marítimo del Callao indicando que los papeles de la citada presa se encontrarían en poder de Salcedo ${ }^{45}$. El 4 de setiembre, el mismo director de marina envió a dicha Mayoría los papeles de mar y demás documentos de esta presa ${ }^{46}$.

Del mismo modo, en julio de 1867, el director de marina ordenó al mayor de órdenes del Departamento Marítimo del Callao que solicitase al capitán de corbeta Gregorio Pérez que entregase los planos del "vapor torreón Huáscar que se trajo consigo al separarse de la Escuadra. A más del ningún derecho que tiene el citado oficial para haber tomado y retenido con arbitrariedad tales objetos, son hoy de indispensable necesidad para practicar un estudio prolijo de este vapor, como lo manifiesta el señor Comte Gral de la División naval del Perú” [sic] ${ }^{47}$.

Las continuas evasiones tuvieron como resultado que los jefes y oficiales arrestados en el Callao fueran desembarcados

44 Elcorrobarrutia, Director de Marina, al Mayor de Órdenes encargado de la Comandancia General del Departamento Marítimo del Callao, fol. 24. (A.H. de M.).

45 Dirección de Marina. Copiador de notas a diferentes autoridades. Elcorrobarrutia al Capitán de Navío comandante de la División Naval Peruana en Chile, 22-VIII-1866, fol. 10 (A.H. de M.).

46 Elcorrobarrutia, Director de Marina, al Mayor de Órdenes encargado de la Comandancia General del Departamento Marítimo del Callao, 4-IX1866, fol. 14. (A.H. de M.).

47 Elcorrobarrutia, Director de Marina al Mayor de Órdenes del Departamento Marítimo del Callao, 25-VII-1867, fol. 151 (A.H. de M.). 
y llevados durante la primera quincena de noviembre a la isla de San Lorenzo para que cumplieran con su prisión. Para ello, el Gobierno comunicó a través del prefecto del Callao -el coronel Manuel G. La Cotera, quien reemplazó al coronel de infantería Mariano Herencia Cevallos (El Comercio, 21 de setiembre de 1866, número 9086)- al comerciante Tadeo Terry que su casa ubicada en la isla era requerida temporalmente para tal fin. Los marinos fueron desembarcados en la isla en el atardecer del martes 13 de noviembre (El Comercio, 14 de noviembre de 1866, número 9148).

Ante la respuesta afirmativa de Terry, la tesorería de la provincia del Callao invirtió cuatrocientos tres soles con veinticinco centavos en jornales de carpintería y artículos de refacción de la misma ${ }^{48}$.

Luego de que los jefes y oficiales enjuiciados pasaron al primer puerto a la espera del veredicto de su juicio, en enero de 1867, la casa de Terry fue transferida a la prefectura del Callao

48 Dirección de Marina. Copiador de notas a diferentes autoridades, Elcorrobarrutia al Prefecto del Callao, 24-X-1866, fol. 62 (A.H. de M.). Notas de la Secretaría de Guerra y Marina del año 1866. Nro. 1284, 23-X-1866, fol. 97 (A.H. de M.). Dirección de Marina. Copiador de notas a diferentes autoridades, Elcorrobarrutia al Tesorero de la Provincia Litoral del Callao, 17-XI-1866, fol. 84 (A.H. de M.). Tadeo Terry fue "un próspero empresario peruano, quien a mediados del siglo XIX poseía en la caleta Paraíso una importante factoría de vapor, con talleres de carpintería y herrería, donde se torneaba, componía y fabricaba cualquier pieza de maquinaria para los vapores que realizaban el servicio de la costa, asimismo, obtuvo la concesión para construir y operar el primer dique flotante peruano y también tuvo a su cargo el faro de madera ubicado en la parte más elevada del cerro del cabezo [...] [luego] del combate naval del 2 de mayo de 1866 [los españoles] tomaron las instalaciones de la factoría de Terry, destruyéndola y utilizando su excelente madera de roble inglés en la reparación de sus buques" (Hudtwalcker Morán 2008: 66). 
(ejercida por el coronel J.J. Inclán) “con el importante objeto de establecer en ella [...] el lazareto donde deben medicinarse los epidemiados de fiebre amarilla que procedan del extranjero ${ }^{49}$.

Volviendo al caso de los marinos enjuiciados, en el libro copiador de la Dirección de Marina, existe una comunicación que Bustamante le dirige al gran mariscal Antonio Gutiérrez de la Fuente, quien era el presidente del Consejo de Guerra de Oficiales Generales, para indicarle que el juicio a los marinos se haría el 21 de diciembre en el fuerte Santa Catalina ${ }^{50}$.

Al inicio, este Consejo estuvo conformado por el citado presidente e integrado por los generales de división José Rufino Echenique ${ }^{51}$ y Fermín del Castillo, los de brigada Pedro Cisneros ${ }^{52}$, Nicolás Freyre ${ }^{53}$, Rudecindo Beltrán, Juan José Arrieta y Luis La Puerta, así como por el contralmirante Francisco Forcelledo ${ }^{54}$. Los ayudantes del Consejo

49 Dirección de Marina. Copiador de notas a diferentes autoridades, Elcorrobarrutia al Prefecto del Callao, 22-I-1867 (A.H. de M.).

50 El Consejo de Guerra de Oficiales Generales se creó en el Callao el 1ro de mayo de 1866 con la finalidad de absolver los casos presentados por la dictadura (Echenique 1952 II: 277). El artículo $2^{\circ}$ decretaba que: "Este Consejo, además de las funciones que las leyes militares le confieren, está llamado a ilustrar al Gobierno en todos los casos difíciles en que éste le consulte [...]" (Aranda VI 1896: 828).

51 Figura como Presidente de la Cámara de Diputados de la República en 1865 (Cabello, 1865: 84).

52 Figura como Senador de la República en 1865 (Cabello 1865: 83).

53 En 1860 fue Comandante General de la Marina (Romero Pintado 1984: 99). Figura como Senador de la República en 1865 (Cabello 1865: 83).

54 (Arequipa 1805-Lima 6/6/1873). Casó por palabra de presente el 23 de febrero de 1846 con Josefa Tristán, hija de Pío Tristán y de Joaquina Flórez de Tristán, siendo testigos de su matrimonio el presidente de la República, Ramón Castilla y Francisca Canseco, su esposa. Expediente 
fueron el coronel Norberto Eléspuru, el teniente José M. López y José Pérez Vargas. El ayudante del presidente fue el sargento mayor Antonio G. de la Fuente. También lo integraban los coroneles Joaquín Torrico y Manuel Santiago Gómez. El ayudante del primero fue el sargento mayor Luis Elcorrobarrutia, mientras que el del general La Puerta fue José Stevenson. Asimismo, José Allende, Manuel Vicente Morote, Felipe Rivas, Juan Salaverry, Rosendo Carreño, Tomás Gutiérrez, Pío Jorge Echenique y N. Gutiérrez completaban la lista (El Peruano, 12 de mayo de 1866, tomo 50, número 42, p. 157).

Para el caso de los marinos enjuiciados estuvo integrado, además, por el general de brigada Baltazar Caravedo, siendo asesor del Consejo el auditor de marina doctor Agustín Fuentes Chávez" ${ }^{\prime 5}$.

La comunicación donde se designaba a Santa Catalina como lugar del juicio figura como "No corre", y se elevó otra, esta vez por parte de José Elcorrobarrutia indicándole que el lugar donde se realizaría el juicio sería la Cámara de Oficiales de la fragata Apurimac ${ }^{56}$.

Francisco Forcelledo Maldonado, caja f4, sobre f0164, fol.2 (A.H. de M). Él y su hijo Francisco, quien era guardiamarina, lucharon en el combate naval del 2 de Mayo (Ortiz y Castañeda 2007: 107). Otro hijo, Sócrates, luchó en Abtao a bordo de la América. El Peruano, miércoles 6 de junio de 1866, tomo 50, número 52, p. 208.

55 El doctor Agustín de la Fuente y Chávez fue auditor general de Marina y asesor de aduanas (El Comercio, 1 de octubre de 1866, número 9107).

56 Dirección de Marina. Copiador de notas a diferentes autoridades, Bustamante al Presidente del Consejo de Oficiales Generales, 19-XII-1866, fol. 102 (A.H. de M.). Elcorrobarrutia al Presidente del Consejo de Oficiales Generales, 19-XII-1866, fol. 103 (A.H. de M.). 
Para esto, el presidente del Consejo de Guerra de Oficiales Generales informó, el 12 de diciembre a Prado, que este se encontraba incompleto para realizar el proceso debido a que los generales Forcelledo, Arrieta y Beltrán se encontraban enfermos. Al respecto, G. de la Fuente recomendó al jefe supremo provisorio que para completar el número de vocales sería conveniente nombrar a un oficial general de Marina.

El designado por el ejecutivo fue el contralmirante Domingo Valle Riestra" ${ }^{57}$, quien "debe conocer y fallar la causa seguida a los Jefes y oficiales de marina que actualmente se hallan en la Ysla de San Lorenzo" $[\text { sic }]^{58}$.

A los dos días, Valle Riestra se excusó ante Prado de ser parte del Consejo y fue reemplazado por el general de división Manuel Martínez de Aparicio ${ }^{59}$. Luego de esto, Va-

57 Figura como senador de la República por la provincia litoral del Callao, en 1865 (Cabello 1865: 84). Fue enviado extraordinario y ministro plenipotenciario del Perú en Madrid. El 11 de febrero de 1865, recibió la misión de negociar en España el Tratado del 27 de enero de 1865 firmado por Manuel Ignacio de Vivanco y por el jefe de Escuadra José Manuel Pareja y Septien. El 21 de febrero de 1866 se dio por concluida su designación (Aranda 1896 VI: 582-586 y 710).

58 Dirección de Marina. Copiador de notas a diferentes autoridades, Elcorrobarrutia al Contra Almirante D. Domingo Valle Riestra, vocal del Consejo de Guerra de oficiales generales, 12-XII-1866, fol. 97 (A.H. de M.). Dirección de Marina. Copiador de notas a diferentes autoridades, Elcorrobarrutia al Presidente del Consejo de Guerra de Oficiales Generales, 12-XII-1866, fol. 97. (A.H. de M.).

59 Dirección de Marina. Copiador de notas a diferentes autoridades, Elcorrobarrutia al Presidente del Consejo de Guerra de Oficiales Generales, Iltmo Sor. Gran mariscal D. Antonio G. de la Fuente, 14-XII-1866, fol. 99 (A.H. de M.). Dirección de Marina. Copiador de notas a diferentes autoridades, Elcorrobarrutia al General D. Manuel de Aparicio, Vocal del Consejo de Guerra de Oficiales Generales, 14-XII-1866, fol. 99 (A.H. de M.). 
lle Riestra fue nombrado presidente de la junta que debió examinar el proyecto de Reglamento del Cuerpo de Maquinistas de la Armada, el cual estaba integrado por los capitanes de navío Diego de la Haza (presidente de la Junta de Reconocimiento), José Rosendo Carreño (superintendente de la Factoría de Bellavista), Manuel Villar (comandante de la fragata Apurímac), capitán de fragata Amaro G. Tizón (mayor de órdenes del Departamento de Marina), capitán de corbeta Enrique Espinar (comandante del monitor Loa), Nicolás del Portal (comandante del vapor Sachaca), Daniel de la Rosa y Arturo Valdivieso (comandante del monitor Victoria) $^{60}$.

El Consejo de Guerra continuó su deliberación de forma regular hasta enero de 1867, cuando una enfermedad de Martínez de Aparicio tuvo como resultado que el Consejo de Generales fuera interrumpido. Al respecto, Prado intentó reemplazarlo con el general de brigada Manuel Vicente Morote $^{61}$. Sin embargo, al día siguiente, por iniciativa de Gutiérrez de la Fuente se dejó sin efecto este cambio de vocales debido a que Martínez de Aparicio se había restablecido $^{62}$.

60 Dirección de Marina. Copiador de notas a diferentes autoridades, Elcorrobarrutia al Contra Almirante D. Domingo Valle Riestra, 19-XII-1866, fol. 103 (A.H. de M.).

61 Dirección de Marina. Copiador de notas a diferentes autoridades, Elcorrobarrutia al Presidente del Consejo de Guerra de Oficiales Generales, Gutiérrez, 30-I-1867, fol. 130 (A.H. de M.).

62 Dirección de Marina. Copiador de notas a diferentes autoridades, Elcorrobarrutia al Presidente del Consejo de Guerra de Oficiales Generales, Gutiérrez, 31-I-1867, fol. 131 (A.H. de M). Por otro lado, se dio licencia por seis meses al capitán de corbeta Arístides G. Vigil para que recupere su salud trasladándose a los departamentos del Sur. Dirección de Mari- 
Como se observa, diversos inconvenientes impidieron la reunión del Consejo de Generales para examinar la causa de los marinos enjuiciados. La posible impopularidad del juicio entre los flamantes héroes nacionales de la denominada "segunda independencia" sería el motivo de la dilatación en el proceso así como de las excusas de algunos oficiales generales nombrados a formar parte del Consejo.

En enero de 1867, Prado dispuso que el Consejo de Generales se reúna en el arsenal -donde los jefes y oficiales permanecerían arrestados- y en el local "de la extinguida Comandancia General de Marina"63. Ese mismo día, 22 de enero, Prado aceptó la renuncia del coronel Joaquín Torrico al cargo de juez fiscal "en la causa que se ha mandado seguir a los Jefes y oficiales de Marina que han abandonado el arresto que se les tiene impuesto en la Isla de S. Lorenzo" "64. Sin embargo, su nombre aparece durante las defensas jurídicas posteriores.

Sin embargo, y por razones desconocidas, el jefe supremo modificó la orden de arresto en el arsenal y dio como prisión de los marinos a "la ciudad del Callao, la que tendrá[n] por cárcel" "65. Se fijó el 25 de enero para que el Consejo de Guerra de Oficiales Generales celebrase, conociera y fallase

na. Copiador de notas a diferentes autoridades, Elcorrobarrutia al Juez Fiscal, Torrico, 18-I-1866, fol. 120 (A.H. de M.).

63 Elcorrobarrutia, Director de Marina al Mayor de Órdenes del Departamento Marítimo del Callao, 22-I-1867, fol. 84 (A.H. de M.).

64 Dirección de Marina. Copiador de notas a diferentes autoridades, Elcorrobarrutia al Juez Fiscal, Torrico, 22-I-1867, fol. 124 (A.H. de M.).

65 Elcorrobarrutia, Director de Marina al Mayor de Órdenes del Departamento Marítimo del Callao, 23-I-1867, fol. 85 (A.H. de M.) La población del Callao ascendía a 17,539 habitantes (Cabello 1866: 71). 
en la "causa seguida de Orden Suprema a los Jefes y oficiales de Marina que pertenecieron a la Escuadra de operaciones del Sur, y que hoy tienen por lugar de arresto la ciudad del Callao $[\ldots]^{\prime \prime 66}$.

Un caso curioso ocurrió cuando el coronel Torrico, por indicación de Gutiérrez de la Fuente, solicitó al Ramo de Guerra y Marina que le abonasen 80 soles para que cada uno de los miembros del Consejo de Guerra pueda trasladarse desde Lima al Callao en ferrocarril. Al respecto, Prado les respondió que no aceptaba esa solicitud "por no ofender el decoro de dichos Señores, y por consideraciones y respetos debidos al elevado cargo que invisten en la carrera militar" (Arosemena 1975: 48 y 51) ${ }^{67}$. A los dos días de la respuesta de Prado, se comunicó a Gutiérrez que mientras funcionase el Consejo de Guerra sus integrantes podían hacer uso del vagón del gobierno ${ }^{68}$.

\section{Durante el juicio}

Entre los oficiales acusados, algunos habían luchado en Abtao o en el Callao, y otros, incluso en ambos combates. Asimismo, ocurría que la mayoría de estos marinos se encontraban inmersos dentro de lo que Romero Pintado distinguió en la Institución naval de esta época:

66 Elcorrobarrutia, Director de Marina al Mayor de Órdenes del Departamento Marítimo del Callao, 24-I-1867, fol. 85 (A.H. de M.).

67 Dirección de Marina. Copiador de notas a diferentes autoridades, Elcorrobarrutia al Juez Fiscal, Torrico, 22-I-1867, fol. 124 (A.H. de M).

68 Dirección de Marina. Copiador de notas a diferentes autoridades, Elcorrobarrutia al Presidente del Consejo de Guerra de Oficiales Generales, Gutiérrez, 24-I-1867, fol. 126 (A.H. de M.). 
Más puede afirmarse que en la Marina no había oficiales cuyos hogares hubieran pertenecido a la clase trabajadora y que, en cambio, a partir de Vivanco y siguiendo con Castilla, Echenique, San Román, Prado, Balta y Pardo y Lavalle, presidentes todos del Perú, cuando no hubo un oficial que fuera su hijo, no faltó un hermano, o un sobrino; y que se dieron los casos de dos y hasta tres miembros de las familias de hombres que pertenecían al pequeño grupo dirigente nacional por su ancestro, su riqueza, su destacada posición intelectual o su importante peso político (Romero Pintado 1984: 125).

Sobre la aprobación y admiración popular, esta se encontraba en pugna en las páginas de El Comercio, no siendo el caso en el diario oficial El Peruano donde no se mencionó el proceso ni dato relacionado con los marinos enjuiciados. De hecho, entre los artículos que se publicaron en el diario de La Rifa sobre el tema de "los marinos" puede concluirse que los defensores de los acusados, así como los que apoyaron la decisión del gobierno sostuvieron no muchos intercambios de pareceres, algunos de modo intenso, otros, algo etéreos.

La convocatoria a elecciones para presidente de la República y representantes al Congreso Constituyente, la polémica en Piura de Santiago Távara, las de Juan Mariano Goyeneche y Barreda con Juan Antonio Menéndez, la cuestión Bogardus, los telegramas que informaban sobre la guerra en Europa y 48 en el Paraguay, entre otros temas, aparecen con mayor frecuencia opacando la "cuestión de marina".

Sin embargo, la publicación de artículos que acusaban la actitud de los marinos enjuiciados demuestra la división de posturas en este círculo. Por ejemplo, el anónimo "un amigo de Salcedo" (en referencia al capitán de navío José María Salcedo), publicó una hiriente e intensa nota en la que sostuvo: 
Hablamos con vosotros la pacotilla de gefes y oficiales detenidos en San Lorenzo y enjuiciados: con vosotros á quienes tanto y tanto ha dolido el que un fiscal severo os acuse de traidores á la Patria [] Hablamos con vosotros los que tan ensañados y rencorosos os mostrais con aquellos de vuestros antiguos compañeros, que, mas subordinados y menos pretenciosos que vosotros [] cumpliendo así, ellos, con el mas sagrado de sus deberes y dando claras muestras de su moralidad militar y disciplina: Hablamos con vosotros, en fin, á quienes la voz pública [] comienza á designar con el epíteto de rabi-atados [] Bajo el pretesto tan necio como futil de que no era honroso para vosotros poneros a órdenes de un jefe extranjero, renunciasteis en masa vuestros cargos, dejando así poco menos que del todo abandonados los buques que la Nación peruana había confiado á vuestro patriotismo [] y desesperados al ver la improbacion pública fríamente estampada en todos los semblantes, os desatáis en contra de los que no participaron á ciegas de vuestras ideas caprichosas y pueriles " $y$ hablais con énfasis despreciativo de Pardo de Zela y Garcia, tratando de desprestigiarlos” [][se dice de vosotros] "acostumbrados, en la alternativa de nuestras guerras civiles, á ser dados de baja hoy para verse admitidos nuevamente en el servicio y aun ascendidos mañana, los marinos desobedientes no han trepiado en seguir su capricho actual, comportándose como chicos mal criados" [] Hemos notado que respecto á la conducta de los marinos sometidos á juicio la prensa ha guardado el mas profundo silencio [sic] []" (El Comercio, 6 de octubre de 1866, número 9113) ${ }^{69}$.

Asimismo, este diario sirvió para que los propios enjuiciados presentasen sus descargos públicos a hechos que los involucraban. Uno de estos, Lizardo Montero, ante el conocimiento de que el capitán Carlos Varea -según Melo guardia-

69 Sobre la mención a Juan Pardo de Zela Urizar, se refiere a la acusación de negligente y buen marino de tierra, que se le hace. Esto debido a que en junio de 1865 se encontró en Pisco al mando de la América y la entregó sin luchar a Montero, que comandaba al Amazonas (Melo 1911: 50). 
marina- se había sublevado a bordo de la Unión vivando su nombre, sostuvo que: "como mis enemigos ó malquerientes pudieran apoyarse en mi silencio para dañar mi honra; me veo precisado á protestar ante la opinión pública de un atentado escandaloso acaecido en un puerto extranjero que jamás hubiera autorizado, y que muy al contrario lo reprueba mi bien probado patriotismo"(El Comercio, 13 de octubre de 1866, número 9119). El 4 de diciembre, desde la isla de San Lorenzo, volvía a sostener que "ni directa, ni indirectamente he dado lugar y pretexto para que se tome mi nombre ( $E l$ Comercio, 6 de diciembre de 1866, número 9168).

Lo peculiar del hecho es que Varea, al ser destinado a la Escuadra peruana comandada por Montero, este "lo rechazó, haciéndolo regresar" a Lima (El Comercio, 18 de octubre de 1866, número 9123). Werlich presenta a Varea con la intención de liberar a Montero y sublevarse contra Prado (Werlich 2010: 147). Melo lo hace apoyando a Balta (Melo 1911: 52).

El soporte a los enjuiciados, aunque algunos de manera singular, sirvieron para equilibrar este "ataque y contraataque" mediático. El ministro peruano saliente en el Brasil, Buenaventura Seoane, envió una carta pública desde Filadelfia, Estados Unidos de Norteamérica, donde daba cuenta de su participación en el apoyo al capitán de fragata Aurelio García

y García cuando la Independencia arribó a Río de Janeiro desde Europa. Terminó escribiendo que "si algún influjo tuvieran mis palabras ante el Gobierno, no concluiría sin pedirle su inmediata restitución al mando de la fragata, por conciencia que tengo, no solo de que es uno de los mas brillantes jefes de nuestra escuadra, sino de que su nombre estará en la primera ocasión, asociado a una gloria nacional" (El Comercio, 19 de octubre de 1866, número 9124). 
Asimismo, cartas de José Pardo y Aliaga, Manuel Blanco Encalada y Vicente Villalón (comandante general de la Marina de Chile, 1866-1867) desmentían públicamente las acusaciones de inmoralidad e indisciplina en la división naval peruana durante el comando de Montero ${ }^{70}$. De las tres, puede considerarse como la de mayor influencia la escrita por Blanco Encalada:

Señor D. Lizardo Montero

Estimado comandante

"[...] los rumores, desfavorables sobre la inmoralidad, y disciplina de la escuadra que U. mandaba no tenian fundamento sino en los enemigos de UU. personales ó políticos. La independencia y Huascar recientemente llegados á Valparaiso con malísimas tripulaciones necesitaron organizarse, estos asearse y pintarse despues de una larga navegación y se encontraban apenas en los primeros ejercicios doctrinas por las causas espuestas [sic]. Por lo que toca á las corbetas puedo asegurar que su disciplina y órden era inmejorable y muy particularmente en la Unión que yo montaba pude cerciorarme de ello. Por otra parte mi estimado amigo, la opinión de su país debe de conocerse por el convencimiento que deba tener de los conocimientos, carácter y actividad que los distinguen, y sobre la cual la mentira y mala voluntad no puede ejercer imperio. Creame U. siempre su afectísimo amigo. Manuel Blanco Encalada" [sic] (El Comercio, 1 de noviembre de 1866, número 9136).

El abogado defensor de Miguel Grau fue Luciano Benjamín Cisneros, quien en la primera parte de su alegato reconoció que la cuestión del juicio había trascendido desde lo estrictamente jurídico hacia lo político. De hecho, en un primer momento parece que validó la decisión de Prado al estimar

70 José Antonio García y García sostuvo que José Pardo y Aliaga fue el responsable de desviar los verdaderos hechos sobre lo ocurrido en Valparaíso (García y García 1867: 28). 
"como el primer deber de todo ciudadano apoyar al poder, cualquiera que sea su origen, siempre que aspire leal y honradamente a la felicidad pública" (Secretaría del Ministro de Marina 1984: 81). Sin embargo, luego lo atacó cuando sostuvo que se trata de "defender en la humilde persona de los marinos a la nación contra el gobierno, a los pueblos contra el poder, las purísimas glorias nacionales contra los deslices de una política ligera y poco meditada" (Secretaría del Ministro de Marina 1984: 81).

Acusó al gobierno de haber desvirtuado y exagerado la conducta de estos oficiales cuando pronunció con clara ironía que "en el Perú estamos en la más completa degradación, que no hay virtudes sociales, que el patriotismo es una vana palabra y que vivimos en un carnaval perpetuo, donde los que en un momento antes aparecían como personificación del heroísmo, arrojan después la máscara, para presentarse como traidores de la misma patria, en cuyo nombre osadamente decían sacrificarse" (Secretaría del Ministro de Marina 1984: 82).

En la segunda parte, Cisneros reconoció la cualidad fiscalizadora de la opinión pública. A su juicio, la atención que la población había otorgado al caso la había ubicado del lado de los marinos. Le atribuye el don de la verdad: "La opinión pública no se adhiere a lo que le es indiferente, ni aplaude sino aquello que tiene el sello de la justicia". Recalca la actitud ambivalente, tibia y hasta temerosa por parte del gobierno, pues este trató de mantener bajo cierto aislamiento el proceso. Cisneros argumenta esto cuando sostiene que la dictadura no se apoyó en la opinión pública, pues supo que le era adversa. "El temor a la sanción pública es la debilidad que anuncia la derrota" (Secretaría del Ministro de Marina 1984: 83-84). 
Sobre el delito de insubordinación, el eje defensivo de Cisneros fue que no pudo haber tal debido a que no hubo una orden -"cuando no hay mandato, no hay desobediencia" (Secretaría del Ministro de Marina 1984: 83)-, sino aviso, recomendación y este a su vez, de manera informal, de "amigo a amigo". La respuesta de los marinos fue con la misma clasificación amical, y dentro de esta, la sinceridad de opinión contra el nombramiento de Tucker. De hecho, se observa que en caso de que los marinos no hubieran deseado permanecer fieles a la dictadura e insubordinarse contra ella, tuvieron las herramientas bélicas para levantarse contra la misma, pero no lo hicieron.

Incluso, Cisneros llama la atención de que la opinión profesional de los marinos sobre asuntos exclusivos de su carrera era la autorizada, pues venía de "hombres competentes, y nada tenía de violento, ilegal y absurdo acoger y seguir esa opinión" (Secretaría del Ministro de Marina 1984: 90).

Por su lado, el abogado defensor de Aurelio García y García, su hermano José Antonio, describió las hazañas navales y marineras que habían dado prestigio internacional a los marinos peruanos, quienes eran reemplazados por uno extranjero. Asimismo, contrastó el hecho de que en Chile se convocaba al ya anciano Blanco Encalada para que comandase la escuadra Aliada, no a un foráneo (García y García 1867: 4-8).

Sobre la acusación de deserción, Cisneros es breve y presenta ante el Consejo la ausencia de pruebas que demostrarían la existencia de este delito. Sustentó su alegato en el hecho de que la dictadura envió a oficiales para que reemplazaran a los marinos, y que estos, luego de entregarles el comando de los buques, volvieron al Callao sometidos a las órdenes del Gobierno. Curiosa fue la burla al fiscal Torrico, 
a quien Cisneros tildó, entre líneas, de ignorante: "Risible en extremo es pues, la acusación de deserción y yo siento que haya sido lanzada por el respetable señor fiscal, porque ello revelará a cuantos tengan noticia de este ruidoso juicio, que después de 40 años de guerra civil, en que hemos gastado nuestra vitalidad, nuestras fuerzas, nuestros tesoros, nuestro honor, nuestros hombres [...] aun no sepamos calificar profesionalmente el delito de deserción" (Secretaría del Ministro de Marina 1984: 92).

Con relación al delito de traición a la patria, Cisneros demuestra que la dictadura no contaba con un plan de ataque a España, sino que lo estaba improvisando. La misma contratación de Tucker lo evidenciaría, pues a su juicio, primero debió contarse con el jefe de la escuadra para que elabore el curso de acción: "Por eso se nos habla de expediciones lejanas y peligrosas que, racionalmente discurriendo, no es posible que hayan existido en las altas miras del Gobierno" (Secretaría del Ministro de Marina 1984: 99). En la misma línea, García y García sostuvo que no existió ese plan y que el estado operativo de los buques peruanos dados tanto por Montero como por Tucker hacían imposible emprender dicha campaña. El ingreso al dique en el Callao de la Independencia y del Apurímac, así como del Huáscar, la Unión y la América en Valparaíso lo demostrarían (García y García 1867: 30-31).

Cisneros atribuyó a Tucker carencia de nacionalismo, "sentimiento, que transformando al hombre lo hace superior a sí mismo". Tenía "un noble y valiente corazón; pero no tiene corazón peruano" ni las cualidades de agente diplomático que "necesita profundos conocimientos de la índole y carácter del país: necesita conocer la legislación en sus variados ramos, las regulaciones internacionales [...] necesita poseer 
por lo menos el idioma: y en fin representar al Estado con cuanta cultura y dignidad reclaman tan elevado puesto", inherentes al jefe de una escuadra en campaña (Secretaría del Ministro de Marina 1984: 97-98).

Por su parte, José Antonio García y García agregó que la última guerra naval internacional que tuvo Estados Unidos fue en 1812 y que Tucker había ingresado al servicio en 1826. Se dedicó a destruir la fama de gran marino de Tucker que Prado y su gabinete habían dado a conocer a los marinos peruanos (García y García 1867: 10-12).

Cisneros indicó que en todo el proceso había existido la "Lógica del error. Cuando el espíritu cae en el vértigo, todo lleva el sello de la fatalidad [...] El Gobierno ha levantado un deforme monumento sobre bases de ceniza [...] Los Gobiernos jamás deben gastar sus fuerzas en cuestiones estériles, agotar en ellas su prestigio es traicionar su misión, porque los Gobiernos son la imagen de la Providencia en el mundo" (Secretaría del Ministro de Marina 1984: 100-101).

A estos argumentos se sumó el que los miembros del Consejo eran "políticamente conservadores", muchos ya muy entrados en años y no deseaban dictar una sentencia impopular contra quienes habían expuesto sus vidas en combates contra los buques de la corona hispánica (Werlich 2010: 149). Esto, a pesar de que el mismo Prado había convocado a algunos de ellos para persuadirlos de que su fallo sea desfavorable a los acusados (Echenique 1952 II: 283).

El sábado 9 de febrero de 1867 concluyeron las defensas. Al terminar las audiencias, el tribunal fue absolviendo uno a uno de los acusados, "siendo solemnemente absueltos de 
toda culpa y pena" ${ }^{71}$ (Basadre 1961 IV: 1626; Arosemena 1975: 50). A los ocho días las sentencias fueron aprobadas por el Gobierno. Luego del veredicto realizado por el Consejo de Guerra, se presentó la situación de qué colocación otorgar a los marinos absueltos dentro de la Armada ${ }^{72}$.

\section{Luego del fallo}

Es así que Prado, quien fue el promotor del juicio, dispuso en marzo de 1867 que dichos oficiales presenten su licencia indefinida ${ }^{73}$. A las pocas semanas, se concedió licencia para navegar en la marina mercante a los capitanes de fragata $\mathrm{Ma}$ nuel Ferreyros y Miguel Grau, esto con el goce de la pensión que les correspondía debido a su condición de indefinidos ${ }^{74}$. Este último se casaría en abril.

Aurelio García y García, Gregorio Pérez, Julio Tellería, Nicanor Asín y Gaspar Ureta fueron enviados a comandar los buques de la nueva Compañía Nacional de Vapores. Esta empresa estatal fracasó por la aparente inoperancia de las embarcaciones que la conformaban (Vegas García 1973: 141).

71 Capitán de Fragata Aurelio García y García. Relaciones Historiadas. Libro Copiador nro. 1, fol. 55.

72 "Remito a U. copia auténtica de la sentencia pronunciada el día 11 del presente, por el Consejo de Oficiales Generales, en la causa seguida a los Jefes y oficiales de Marina, a que dicha sentencia se contrae; y así mismo del Supremo Decreto fecha 13 del propio mes, por lo cual ha sido aprobada [sic] para su publicación en la orden general de la Armada. Elcorrobarrutia”. Elcorrobarrutia, Director de Marina al Mayor de Órdenes del Departamento Marítimo del Callao, 15-II-1867, fol. 97. (A.H. de M.).

73 Elcorrobarrutia, Director de Marina al Mayor de Órdenes del Departamento Marítimo del Callao, 12-III-1867, fol. 103 (A.H. de M.).

74 Elcorrobarrutia, Director de Marina al Mayor de Órdenes del Departamento Marítimo del Callao, 3-IV-1867, fol. 111 (A. H. de M.). 
En mayo, se destinó a la División Naval del Perú de la Escuadra Aliada al teniente primero graduado Enrique N. Alayza, al teniendo segundo Francisco Terry y a los alféreces de fragata Demetrio Ferreyros, Luciano Arana, Arnaldo Larrea, Carlos Herrera y Enrique Palacios ${ }^{75}$. El alférez de fragata Vicente Espinosa fue destacado como dotación del Victoria ${ }^{76}$.

Asimismo, se nombró al capitán de corbeta Juan B. Cobián, "que se hallaba sin colocación", como segundo comandante de la fragata $A$ purímac ${ }^{7}$, y se designó como capitanes de puerto al alférez de fragata Justiniano Cavero (ayudante de las Islas de Chincha), teniente primero Francisco Charún (ayudante del puerto del Callao), teniente primero Carlos Thorne (puerto de Santa) y al teniente primero Felipe Mesa (Tambo de Mora) ${ }^{78}$.

Estas designaciones son llamativas debido a que el 22 de julio de 1867 se comunicó que el ministro de Gobierno había promulgado el 19 de ese mes, que la dictadura tenía fundados motivos para creer que la Escuadra Española volvería al Pacífico. Por ello, indicó a los capitanes de puerto que fueran más cautelosos y celosos en sus funciones de control de to-

75 Elcorrobarrutia, Director de Marina al Mayor de Órdenes del Departamento Marítimo del Callao, 18-V-1867, fol. 126 (A.H. de M.).

76 Elcorrobarrutia, Director de Marina al Mayor de Órdenes del Departamento Marítimo del Callao, 12 y 13-VI-1867, fol. 134 (A.H. de M.) El comandante de este buque fue el capitán de corbeta Antonio Valdivieso (Cabello 1867: 226).

77 Elcorrobarrutia, Director de Marina al Mayor de Órdenes del Departamento Marítimo del Callao, 16-VI-1867, fol. 135 (A. H. de M.). El comandante de este buque fue el capitán de navío Manuel Villar (Cabello 1867: 226).

78 Elcorrobarrutia, Director de Marina al Mayor de Órdenes del Departamento Marítimo del Callao, 17-VI-1867, fol. 136 (A.H. de M.). 
dos los pasajeros que arribasen al litoral para así "impedir la entrada de españoles al territorio de la República"79. Lo concreto fue que el 21 de mayo de 1867 el Congreso Constituyente dio la Ley que ordenaba continuar la guerra a España. El cúmplase, regístrese y publíquese de Prado se dio el 13 de junio (Aranda 1896 VI: 959).

Sobre este hecho, fue recién el 2 de octubre de 1879, en plena guerra del Pacífico, que el vicepresidente Luis La Puerta y el canciller Manuel Irigoyen firmaron la ratificación a la aprobación que hizo el Congreso de la República al Tratado de Paz y Amistad entre la República del Perú y el reino de España (Aranda 1896 VI: 1051-1053) ${ }^{80}$.

Por otro lado, el 17 de mayo de 1867, Prado nombró al contralmirante Domingo Valle Riestra comandante general de la División Naval del Perú en la Escuadra Aliada, en reemplazo del capitán de navío José María García, quien asumió la Mayoría de Ordenes del Departamento Marítimo del Callao ${ }^{81}$. La escuadra peruana volvió así al Callao el 2 de febrero de $1868 .^{82}$

Sin embargo, no todos los oficiales involucrados tuvieron un destino claro y fijo. Tal fue el caso del capitán de navío Lizar-

79 Elcorrobarrutia, Director de Marina al Mayor de Órdenes del Departamento Marítimo del Callao, 22-VII-1867, fol. 150 (A. H. de M.).

80 El plenipotenciario del Perú fue Juan Mariano de Goyeneche y Gamio, caballero no profeso de la Orden de Santiago. El plenipotenciario del reino de España fue Mariano Roca de Togores, marques de Molins, grande de España, caballero de la Insigne Orden del Toisón de Oro.

81 Elcorrobarrutia, Director de Marina al Mayor de Órdenes del Departamento Marítimo del Callao, 18-V-1867, fol. 127 y 12-VI-1867, fol. 133 (A.H. de M.).

82 Contralmirante Domingo Valle Riestra. Relaciones Historiadas. Libro Copiador nro. 1, fol. 4 (A.H. de M). 
do Montero, el teniente primero Carlos Ferreyros y los alféreces de fragata Pablo Duffó, Santiago Torrico, entre otros, quienes pasaron revista de comisario como agregados en el Departamento Marítimo del Callao ${ }^{83}$.

\section{Conclusiones}

El desarrollo del proceso, así como el resultado del juicio de los marinos, evidencian que la dictadura de Prado no logró cuajar en la legitimidad popular, pues el hecho de que el resultado haya sido desfavorable a sus intenciones dañó de cierta manera su prestigio obtenido el 2 de mayo de 1866.

Salta a la vista que los cargos fueron sobredimensionados, pues no existía argumento legal que los sostuviese. Esto revela una acusación política atolondrada y sin meditación que solo buscó castigar la firmeza racional y reflexiva contraria a las órdenes de Prado.

La ambivalencia y falta de consistencia entre lo pensado, lo deseado y lo real por parte de la dictadura habría generado estos escenarios contradictorios en los cuales si bien se encontraba en estado de guerra contra España, no se decidía sólidamente ir en campaña hacia sus dominios. Si los buques hubieran estado en óptimas condiciones, si el relevo se hubiera hecho de acuerdo a ordenanza, nada impediría que la Escuadra Aliada zarpara rumbo algún dominio hispánico. Nunca lo hizo. Esto refuerza la postura contraria a la existencia planificada de una acción naval ofensiva.

83 Elcorrobarrutia, Director de Marina al Mayor de Órdenes del Departamento Marítimo del Callao, 12 y 13-VI-1867, fol. 134 (A.H. de M.). 
Las continuas fugas de algunos de los prisioneros, así como las libertades con las que contaron, son prueba de que la dictadura no logró afianzarse en todas las esferas del Estado. Esto en clara alusión a la Armada. Debe recordarse que los marinos presos y enjuiciados habían luchado por la rebelión de Prado contra Pezet. La deslealtad hacia los flamantes vencedores de Abtao y del Callao no debió ser bien entendida por parte de la sociedad peruana, tan dispuesta a apoyar a quienes percibe como víctimas de abusos y acoger a los héroes que tanto anhela.

Finalmente, la demostración de severidad de Prado -mal asesorado o sin asesoramiento- hacia los marinos peruanos que rehusaron servir bajo las órdenes de Tucker sirvió de mala propaganda a su Gobierno, lo que incrementó su deslegitimación y próxima separación.

Recibido: 22 de junio del 2016

Aprobado: 12 de julio del 2016

\section{Bibliografía}

\section{Fuentes primarias}

Archivo Histórico de Marina (A. H. de M.)

\section{Fuentes secundarias}

ARANDA, Ricardo

Colección de los tratados, convenciones, capitulaciones, armisticios y otros actos diplomáticos y políticos celebrados desde la independencia hasta el día. Tomo VI. Lima: Imprenta del Estado. 
AROSEMENA GARLAND, Geraldo

1975 El Almirante Miguel Grau. Sexta edición. Lima: Ministerio de Marina.

BARRIOS, Mario

1970 Historia diplomática de Chile (1541-1938). Barcelona: Ediciones Ariel.

BASADRE, Jorge

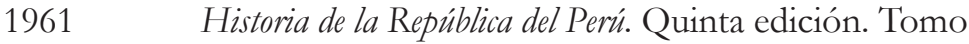
III y IV. Lima: Ediciones Historia.

CABELLO, Pedro M.

1867 Guía política, eclesiástica y militar del Perú para el año de 1867. Lima: Imprenta de la Guía.

1866

Guía política, eclesiástica y militar del Perú para el año de 1866. Lima: Imprenta de la Guía.

1865 Guía política, eclesiástica y militar del Perú para el año de 1865. Lima: Imprenta de la Guía.

ECHENIQUE, José Rufino

1952 Memorias para la historia del Perú (1808-1878). 2 tomos. Lima: Editorial Huascarán.

GARCÍA-CALDERÓN, Francisco

1879 Diccionario de la legislación peruana. 2 tomos. Segunda edición. Lima, París.

GARCÍA Y GARCÍA, José Antonio

1867 Defensa del capitán de fragata don Aurelio Garcia y García, ex comandante de la fragata blindada "Independencia", pronunciada ante el Consejo de Guerra de Oficiales Generales. Lima: Imprenta de Aurelio Alfaro y Cía. 
HUDTWALCKER MORÁN, José A.

2008 "Las islas del Callao en los albores del siglo XX: apuntes para su historia”. Revista de Marina. Año 2008, número 3, pp. 62-77.

LÓPEZ, Jacinto

1947 Manuel Pardo. Lima: Gil S. A.

MELO, Rosendo

1911 Historia de la Marina del Perú. Tomo II. Lima: El Auxiliar del Comercio.

ORTIZ SOTELO, Jorge

2003 Miguel Grau. El hombre y el mar. Lima: Fondo Editorial del Congreso del Perú.

ORTIZ SOTELO, Jorge y Alicia CASTAÑEDA MARTOS 2007 Diccionario biográfico marítimo peruano. Lima: Asociación de Historia Marítima y Naval Iberoamericana.

PUENTE CANDAMO, José A. de la

2003 Miguel Grau. Lima: Instituto de Estudios HistóricoMarítimos del Perú.

ROMERO PINTADO, Fernando

1984 La República - 1850 a 1870. Historia Marítima del Perú. Tomo VIII, vol. 1. Lima: Instituto de Estudios Histórico-Marítimos del Perú.

SECRETARÍA DEL MINISTRO DE MARINA

$621984 \quad$ A la gloria del gran almirante del Perú Miguel Grau. Tercera edición aumentada. Lima: Ministerio de Marina.

THORNDIKE, Guillermo

2006 Grau. La traición y los héroes. Tomo 2. Lima: Fondo Editorial del Congreso de la República, Fondo Editorial de la Universidad San Martín de Porres. 
VEGAS GARCÍA, Manuel I.

1973 Historia de la Marina de Guerra del Perú, 1821-1924. Segunda edición. Lima: Ministerio de Marina.

WAGNER DE REYNA, Alberto

1981 La intervención de las potencias europeas en Latinoamérica1864 a 1868. Historia Marítima del Perú. Tomo VII. Lima: Instituto de Estudios Histórico-Marítimos del Perú.

WERLICH, David P.

$2010 \quad J o h n$ R. Tucker, almirante del Amazonas. Lima: Instituto de Estudios Histórico-Marítimos del Perú, Asociación de Historia Marítima y Naval Iberoamericana. 